\title{
Characterization of Attenuating Properties of Novel Composite Radiation Shields
}

\author{
Abdulraheem Kinsaraa ${ }^{1}$, Ahmed Sherif El-Gizawyab ${ }^{1,2^{*}}$ and Xuewei Mab ${ }^{2}$ \\ ${ }^{1}$ Faculty of Engineering, King Abdulaziz University, Jeddah, Saudi Arabia \\ ${ }^{2}$ College of Engineering, University of Missouri-Columbia, Columbia, Missouri, USA
}

*Corresponding author: Ahmed Sherif El-Gizawyab, University of Missouri, Columbia, Missouri, USA, Tel: 573-489-8593; E-mail: sherifelg@yahoo.com

Received date: September 29, 2016; Accepted date: October 27, 2016; Published date: November 03,2016

Copyright: ( 2016 Kinsaraa A, et al. This is an open-access article distributed under the terms of the Creative Commons Attribution License, which permits unrestricted use, distribution, and reproduction in any medium, provided the original author and source are credited.

\begin{abstract}
Leakage (peripheral dose) of current radiation devices used in treating tumors could have significant side effects on patients' quality of life and life span after radiation treatment. A novel design of sandwich radiation shields is being developed at the present time. This design would provide a unique and adaptable device in shielding danger peripheral radiation reaching healthy organs. The present research aims at determination of attenuating properties of the proposed composite radiation shields using experimental, analytical and numerical simulated techniques. The present work indicates that any of the evaluation techniques could be used successfully with the future development of radiation shield design. The results reveal that the filler material thickness of the composite shield has the strongest effect on the shielding capability of the design. Shell material type and thickness have very little effects on the shielding capability and should only be considered for their load carrying capacity and manufacturability by 3-D printing techniques.
\end{abstract}

Keywords: Radiation shield; Attenuation properties; Material characterization

\section{Introduction}

External beam radiation therapy (EBRT) using X-ray through linear accelerators (LINAC) is being used successfully for radiation therapy of cancer patients [1-5]. Unfortunately, the peripheral dose resulting from leakage and scatter of radiation out of the treating device could cause damage to the surrounding healthy tissues of the patient. Peripheral dose counts for $2 \%$ to $10 \%$ of the maximum dose given to the patient [1]. Additional shielding methods have been introduced in the past to reduce the effects of peripheral doses [6-9]. Most of these methods use garments made out of lead powder-loaded polymer or elastomer sheets. These garments are successful for protecting patients and medical workers from exposing to direct and secondary radiation source during diagnostic imaging in clinics, hospitals and dental offices. However, the garments are not suitable for high dosage treatments. A recent review by the authors Kinsara et al. [1] reveals that despite of recent advancements in linear accelerator (LINAC) and multileaf collimator (MLC) design and technology, the remaining small amount of peripheral dose of these devices still has significant side effects on patients' quality of life and life span after radiation treatment.

Because of the large variation of body size and tumor shape of different patients, it is suggested to have a patient specific design for shields which could reduce the risk of healthy tissues being over radiated. The present joint research at King Abdulaziz University in Saudi Arabia and University of Missouri in USA focuses on the development of the patient specific radiation shield to reduce the peripheral dose to an acceptable level. A novel design of sandwich radiation shields with the outer shell made out of thermoplastics using fused deposition modeling technology (FDM) to fit the patient tightly is under the development at the present time. Filling the printed shell with heavy materials, in the forms of small balls or powder (lead, tungsten, etc.), would provide a unique and adaptable device in shielding danger radiation reaching healthy and sensitive organs of the human body. The plastic shell has to be 3D printed for each patient, while the filling heavy materials are reusable to reduce the cost. In order to optimize the performance and design of the proposed patient specific shields against peripheral doses, the attenuating properties of several combinations of filling materials, geometrical and temporal aspects of the composite shield must be characterized prior to any design iterations. Therefore, the present research aims at determination of attenuating properties of the novel composite radiation shields using experimental, analytical and numerical simulated techniques.

\section{Investigation Approach}

\section{Experimental system design}

Figure 1 displays schematic of the experimental setup for measuring the attenuating properties of different composite shields. Figure 2 shows the physical details of the setup. The Cobalt- 60 radiation source was placed at a distance of $14 \mathrm{~cm}$ away from a Geiger-Mueller detector. The most important element in the experimental system is the GeigerMueller detector for measuring shielding performance of the proposed composite shields. A schematic illustration of the used Geiger-Mueller device is displayed in Figure 3. It is an inert gas ionization detector which uses the Townsend avalanche phenomenon to generate a detectable electronic pulse from as little as a single ionizing event due to a radiation particle. Data acquisition is realized by an ORTEC 776 Counter and Timer system. The Cobalt-60 source, shield and detector are aligned along their centerline. The experimental shield is placed in between the source and the detector at a distance of $13 \mathrm{~cm}$ away from the source to observe the attenuation behavior of the Cobalt- 60 beams. The experimental shield shells are made out of thermoplastic material named polycarbonate (PC) and built by layered manufacturing (LM) technique using the Fused Deposition Modeling (FDM) method on 
Citation: Kinsaraa A, El-Gizawyab AS, Mab X (2016) Characterization of Attenuating Properties of Novel Composite Radiation Shields. J Nucl

Page 2 of 7

STRATASYS's FORTUS $400 \mathrm{mc}$ system. Figure 4 shows the basic design of the target shell. All geometries of these targets are kept constant except the width of the internal cavity (filler material thickness), and the shield material thickness (the shell sides facing the radiation beam). The width changes with the setting of filler material thickness $b$ and shell material thickness $2 c$ (both sides of the shell). Both these geometrical parameters of the target are considered among experimental variables in present research. Figure 5 displays the FDM process used for building the experimental shields. The target shields are filled with different investigated heavy materials prior to testing. The Cobalt-60 source is used in the experiments for simulation of the beam generated by LINAC during radiation therapy. LINAC can deliver X-ray beams in the range of $4 \mathrm{MeV}$ to $20 \mathrm{MeV}$ while Cobalt-60 can emit a gamma ray of $1.17 \mathrm{MeV}$ and $1.33 \mathrm{MeV}$ [10,11]. According to Figure 6 [12], Cobalt-60 has a half-value layer (HVL) and tenthvalue layer (TVL) very close to the energy range of $4 \mathrm{MeV}$ to $20 \mathrm{MeV}$ delivered by LINAC. The blue line on the left in Figure 6 indicates the energy for Cobalt- 60 associated with the TVL for tungsten. The blue line on the right shows another equal TVL for tungsten and the energy range falls above $20 \mathrm{MeV}$. It can be concluded that the energy range between Cobalt-60 and $20 \mathrm{MeV}$ have similar TVLs for tungsten, which means tungsten have similar attenuating properties among this energy range. The same situation is applicable to lead material as well.
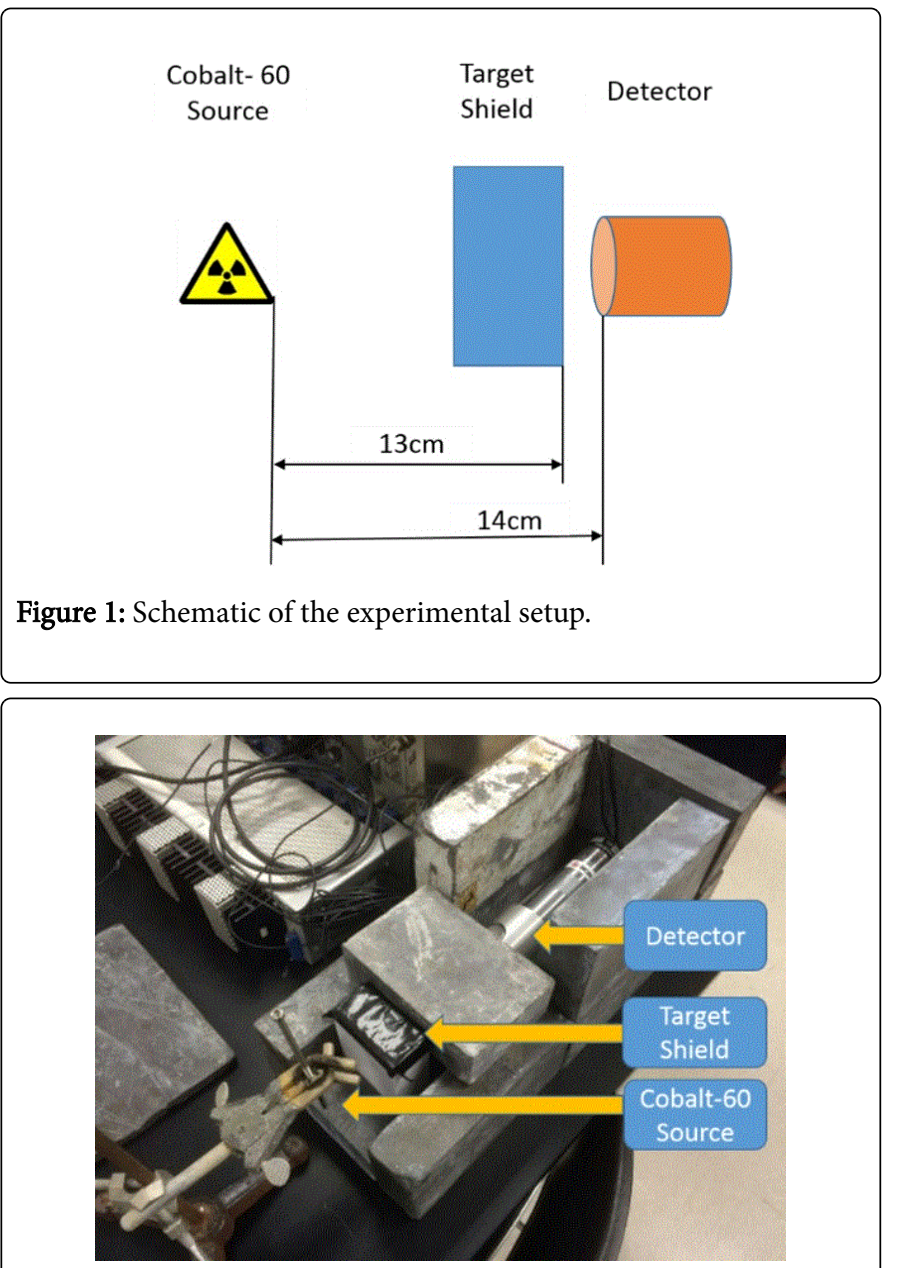

Figure 2: Physical details of the setup.

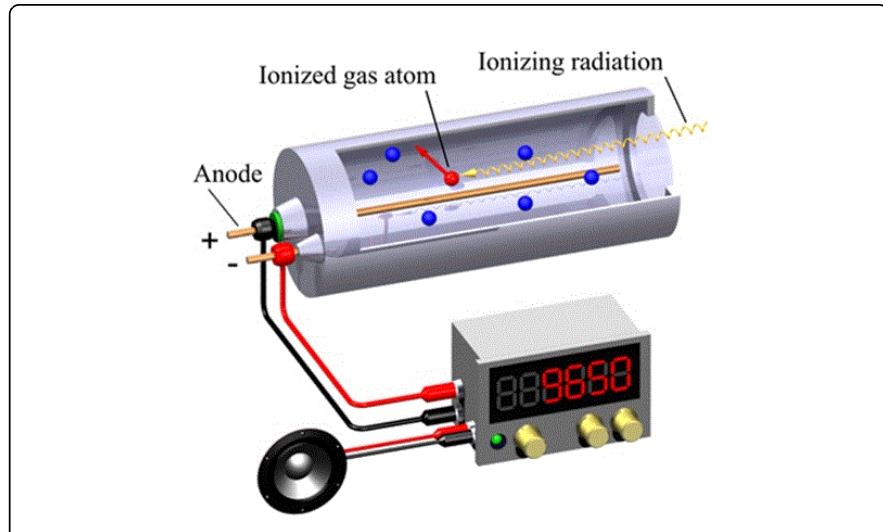

Figure 3: Schematic of a Geiger Muller detector used in the experiments.

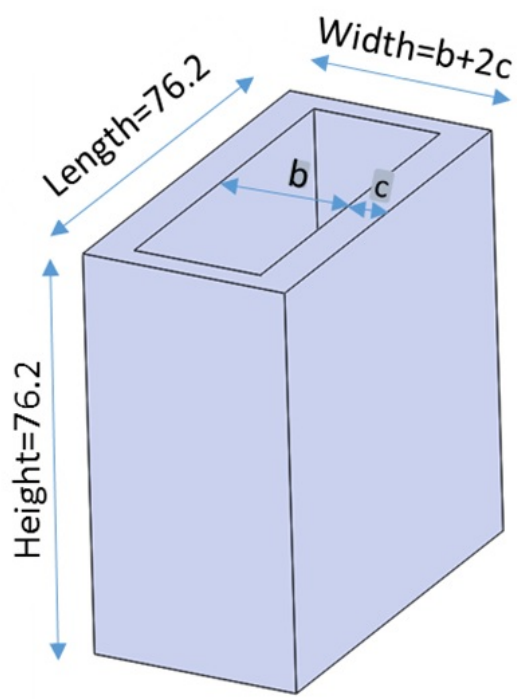

Figure 4: A trimetric view with outer dimensions of the shell design (dimensions are in $\mathrm{mm}$ ).

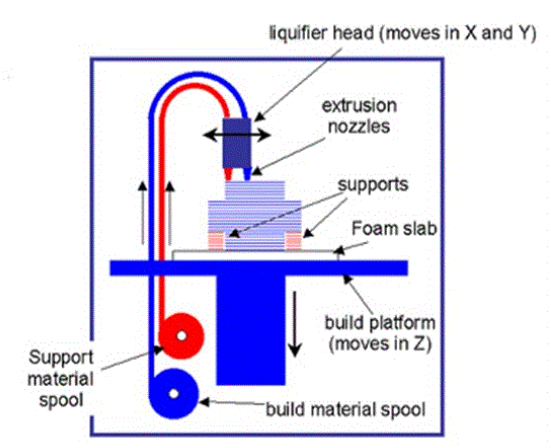

Figure 5: Fusion Deposition Modeling (FDM) technique for building proposed shields. 


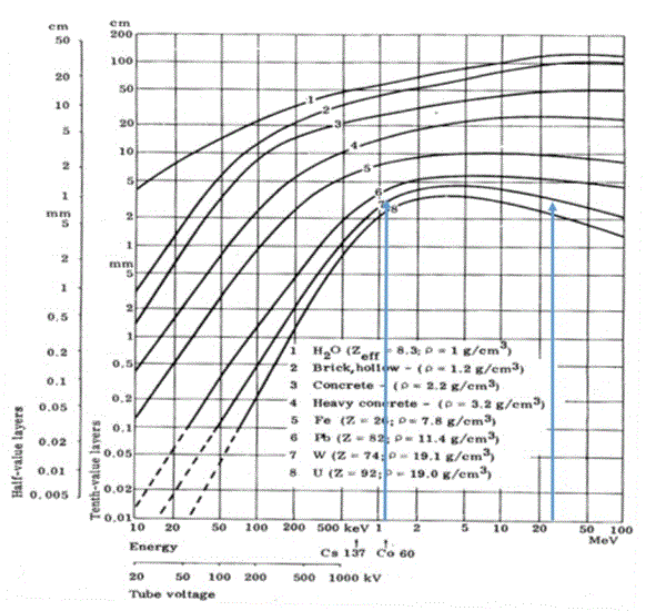

Figure 6: Average HVLs and TVLs of shielding materials [12].

\section{Experimental design and procedures}

The method of partial factorial design using Taguchi's Approach (Robust Process Design) [13], is used in the present work in order to characterize the attenuating properties of investigated radiation shields. The goal of the Taguchi method is to identify the effects of the different control parameters affecting the performance of the composite shields. This technique also allows for determining optimum settings of all factors affecting the design to yield a robust performance (minimum variability). In this design, the independent variables are the Filler Material Type (A), Filler Material Thickness (B), Shell wall Thickness (C) and Exposure Time (D). The outputs (quality characteristics) of the planned experiments include: penetrated photon counts, total photon counts, and blocking percentage of radiation beam. The responses obtained from different experiments are analyzed using response tables and graphical representation of the mean effects of each parameter on the quality characteristics of the design. Signalto-Noise ( $/ \mathrm{N}$ ) Ratio Analysis is used to explore the robustness conditions of the introduced composite shield design. It uses a transformation method to convert the measured responses into $\mathrm{S} / \mathrm{N}$ values. The investigated factors and their levels are summarized in Table 1. Three levels of filler materials are considered: $1 \mathrm{~mm}$ lead balls, $0.2 \mathrm{~mm}$ tungsten powders and $1.5 \mathrm{~mm}$ tungsten balls have been selected for the experiments. Thickness of filler materials (factor B) varies from $5 \mathrm{~mm}, 15 \mathrm{~mm}$, to $25 \mathrm{~mm}$. The shell material is PC, with a volumetric mass density of $1.20 \mathrm{~g} / \mathrm{cm}^{3}$. Shell material thicknesses (factor C) are tested with levels at $10 \mathrm{~mm}, 15 \mathrm{~mm}, 20 \mathrm{~mm}$. Please note that this thickness is the sum of 2 sides of the shield's shell thickness. Exposure time (factor D) is the time that samples are exposed to radiation source. We selected $30 \mathrm{sec}, 60 \mathrm{sec}$ and $100 \mathrm{sec}$ to evaluate if the attenuation ability is affected by the duration of treatment time or not. The control factors and their levels fit Taguchi's L9 standard orthogonal array displayed in Table 2 [13]. The selected array describes nine experimental conditions needed for parametric analysis of the radiation shield Design.

\begin{tabular}{|l|l|l|l|l|}
\hline \multicolumn{5}{|c|}{ Factors } \\
\hline Levels & Filler Material Type (A) & Filler Material Thickness (B) & Shell Material Thickness (C) & Exposure Time (D)/sec \\
\hline 1 & A1 $=1 \mathrm{~mm}$ lead balls & B1 $=5 \mathrm{~mm}$ & C1 $=10 \mathrm{~mm}$ & D1 $=30$ \\
\hline 2 & A2 $=0.2 \mathrm{~mm}$ tungsten powder & B2 $=15 \mathrm{~mm}$ & C2 $=15 \mathrm{~mm}$ & D2 $=60$ \\
\hline 3 & A3 $=1.5 \mathrm{~mm}$ tungsten balls & B3 $=25 \mathrm{~mm}$ & C3 $=20 \mathrm{~mm}$ & D3 $=100$ \\
\hline
\end{tabular}

Table 1: Composite shield design factors and their levels.

\begin{tabular}{|c|c|c|c|c|}
\hline Exp. No. & Filler Material Type (A) & $\begin{array}{l}\text { Filler Material Thickness } \\
(B) / m m\end{array}$ & Shell Material Thickness(C)/mm & Exposure Time (D)/sec \\
\hline 1 & $1 \mathrm{~mm}$ lead balls & 5 & 10 & 30 \\
\hline 2 & $1 \mathrm{~mm}$ lead balls & 15 & 15 & 60 \\
\hline 3 & $1 \mathrm{~mm}$ lead balls & 25 & 20 & 100 \\
\hline 4 & $0.2 \mathrm{~mm}$ tungsten powder & 5 & 15 & 100 \\
\hline 5 & $0.2 \mathrm{~mm}$ tungsten powder & 15 & 20 & 30 \\
\hline 6 & $0.2 \mathrm{~mm}$ tungsten powder & 25 & 10 & 60 \\
\hline 7 & $1.5 \mathrm{~mm}$ tungsten balls & 5 & 20 & 60 \\
\hline 8 & $1.5 \mathrm{~mm}$ tungsten balls & 15 & 10 & 100 \\
\hline 9 & $1.5 \mathrm{~mm}$ tungsten balls & 25 & 15 & 30 \\
\hline
\end{tabular}

Table 2: Experimental log for parametric analysis. 
Page 4 of 7

Nine plastic shells have been printed out and filled with corresponding types of heavy materials. All the experiments have been conducted at the University of Missouri Research Reactor (MURR). Prior to execution of the experimental plan, the situation of the open field without using any shielding in the path of the radiation beam is evaluated. Photon counts are evaluated twice for each of the planed exposure time. The results are presented in Table 3. These results are used in the final analysis to calculate the blocking percentage for each design.

\begin{tabular}{|l|l|l|}
\hline \multirow{2}{*}{ Time } & Total Photon Counts \\
\cline { 2 - 3 } & First Trial & Second Trial \\
\hline 30 seconds & 3121 & 3125 \\
\hline 60 seconds & 6255 & 6252 \\
\hline 100 seconds & 10431 & 10419 \\
\hline
\end{tabular}

Table 3: Total photon numbers under different exposure time.

\section{Analytical prediction of attenuating properties of developed shields}

When a gamma-ray beam traverses an absorber, the intensity of the beam will be attenuated according to the Beer-Lambert's law [14], expressed by equation (1).

$$
I=I_{0} e^{-\mu t}=I_{0} e^{-\left(\frac{\mu}{\rho}\right) t} d=I_{0} e^{-\mu_{m} t} d
$$

Where and I are the un-attenuated and attenuated gamma ray beam intensities respectively. The parameter, $\mu\left(\mathrm{cm}^{-1}\right)$ is the linear attenuation coefficient, $\mathrm{t}(\mathrm{cm})$ is the linear thickness, $\mu \mathrm{m}=\mu / \rho\left(\mathrm{cm}^{2} / \mathrm{g}\right)$ is the mass attenuation coefficient and $\left(\mathrm{g} / \mathrm{cm}^{2}\right)$ is the density thickness of the absorber sample.

If the absorber density is $\rho\left(\mathrm{g} / \mathrm{cm}^{3}\right)$, then the relationship between $t$ and $t_{d}$ is given by equation (2),

$t_{d}=\rho \times t(2)$

The relationship between $\mu$ and $\mu_{\mathrm{m}}$ is given by equation (3).

$\mu=\mu_{m} \times \rho$

HVL is calculated by equation (4).

$\mathrm{HVL}=\frac{\ln 2}{\mu}=\frac{0.693}{\mu}$

Where $\mu\left(\mathrm{cm}^{-1}\right)$ is the linear attenuation coefficient of the shield.

With Cobalt-60 source, lead and tungsten have $12.5 \mathrm{~mm}$ and 7.9 $\mathrm{mm}$ of HVL, respectively [15]. Rearrange Equations (1), (2) and (4), the mass attenuation coefficient can be expressed as equation (5).

$$
\mu_{\mathrm{m}}=0.693 / \mathrm{HVL} \times \rho(5)
$$

Here the volumetric mass density is applied to the equations to serve as the material's apparent density. The volumetric mass densities $\left(\rho_{\mathrm{v}}\right)$ of lead balls, tungsten powder and tungsten balls are $7.4 \mathrm{~g} / \mathrm{cm}^{3}, 9.6$ $\mathrm{g} / \mathrm{cm}^{3}$ and $11.5 \mathrm{~g} / \mathrm{cm}^{3}$ respectively. Then the penetration percent of heavy materials $\mathrm{P} 1$ can be calculated by equation (6).

$$
P_{1}=\frac{I}{I_{0}} \times 100 \%=e^{-\mu_{m} \rho_{v} \cdot t} \times 100 \%
$$

We used water with the density of $1.2 \mathrm{~g} / \mathrm{cm}^{3}$ to substitute the blocking effect of PC. When radiation is from Cobalt-60 the mass attenuation coefficient of water $2.13 \times 10^{-2} \mathrm{~g} / \mathrm{cm}^{3}$. Thus the penetration percent of shell material $\mathrm{P}_{2}$ can be calculated by equation (7).

$$
P_{2}=\frac{I}{I_{0}} \times 100 \%=e^{-\mu_{m} \cdot \rho^{*} t} \times 100 \%
$$

Then the blocking percent, B\%, can be calculated by equation (8).

$$
\mathrm{B} \%=\left(1-P_{1} \times P_{2}\right) \times 100 \%
$$

It should be mentioned that exposure time (factor D) and scattering contribution are not considered in the above analytical model.

\section{Simulated Prediction of Attenuating Properties of the Developed Shields}

A simulation approach using numerical techniques and based on MicroShield code developed by Grove Engineering, Inc., is used to assess attenuating properties of developed Shields. MicroShield is comprehensive photon/gamma ray shielding and dose assessment software that is popular for developing radiation shields and evaluating the radiation source strength [16]. The thicknesses and volumetric mass densities of shell and filling materials are used with the Micro Shield code following the planned nine shield designs. The used simulation code does not consider exposure time (factor D) as contributing factor. The shell material (PC) is considered as water with the density of $1.2 \mathrm{~g} / \mathrm{cm}^{3}$. Unlike the situation with the analytical model, the scattering of photons while interacting with the shield is considered in the simulation model.

\section{Results and Discussions}

\section{Experimental results}

The blocking percentage is identified as the response for each test and it is calculated from the following equation (9).

Blocking Percentage $=\left(1-\frac{\text { Penetrated Photon Counts }}{\text { Total Photon Counts }}\right) \times 100(9)$

This is larger the better case since the larger the blocking percentage means the better attenuation property. Signal-to-noise ratio ( $\mathrm{S} / \mathrm{N}$ ratio) for larger-the-better characteristics was used. The $\mathrm{S} / \mathrm{N}$ ratio was calculated for each output observation using equation (10): 
Citation: Kinsaraa A, El-Gizawyab AS, Mab X (2016) Characterization of Attenuating Properties of Novel Composite Radiation Shields. J Nucl

Page 5 of 7

$$
\mathrm{S} / \mathrm{N}=\eta=-10 \log \left(\frac{1}{n} \sum_{i=1}^{n} \frac{1}{y_{i}^{2}}\right)(10)
$$

Based on all the data recorded, we have calculated the mean, variance; mean squared deviation (MSD), and the $\mathrm{S} / \mathrm{N}$ ratio for each experiment, shown in Table 4.

\begin{tabular}{|c|c|c|c|c|c|c|c|c|c|c|c|c|c|}
\hline \multirow[b]{2}{*}{$\begin{array}{l}\text { Exp. } \\
\text { No }\end{array}$} & \multirow[b]{2}{*}{ Filler Material Type (A) } & \multirow[b]{2}{*}{$\begin{array}{l}\text { Filler } \\
\text { Material } \\
\text { Thickness } \\
\text { (B)/mm }\end{array}$} & \multirow[b]{2}{*}{$\begin{array}{l}\text { Shell } \\
\text { Material } \\
\text { Thickness } \\
\text { (C) } / \mathrm{mm}\end{array}$} & \multicolumn{2}{|c|}{$\begin{array}{l}\text { Penetrated } \\
\text { Photon }\end{array}$} & \multicolumn{2}{|l|}{$\begin{array}{l}\text { Total } \\
\text { Counts }\end{array}$} & \multicolumn{2}{|c|}{$\begin{array}{l}\text { Blocking } \\
\text { Percentage }\end{array}$} & \multicolumn{4}{|c|}{ Large the Better } \\
\hline & & & & $\begin{array}{l}\text { First } \\
\text { Trial }\end{array}$ & $\begin{array}{l}\text { Second } \\
\text { Trial }\end{array}$ & First Trial & $\begin{array}{l}\text { Second } \\
\text { Trial }\end{array}$ & First Trial & $\begin{array}{l}\text { Second } \\
\text { Trial }\end{array}$ & Mean & Variance & MSD & $\mathrm{S} / \mathrm{N}$ \\
\hline 1 & $1 \mathrm{~mm}$ lead balls & 5 & 10 & 30 & 2562 & 2667 & 3121 & 3125 & 17.91 & 14.66 & 16.28 & 5.3 & 24.1 \\
\hline 2 & $1 \mathrm{~mm}$ lead balls & 15 & 15 & 60 & 3662 & 3673 & 6255 & 6252 & 41.45 & 41.25 & 41.35 & 0.02 & 32.33 \\
\hline 3 & $1 \mathrm{~mm}$ lead balls & 25 & 20 & 100 & 4302 & 4409 & 10431 & 10419 & 58.76 & 57.68 & 58.22 & 0.58 & 35.3 \\
\hline 4 & $\begin{array}{l}0.2 \mathrm{~mm} \text { tungsten } \\
\text { powder }\end{array}$ & 5 & 15 & 100 & 8004 & 7957 & 10431 & 10419 & 23.27 & 23.63 & 23.45 & 0.07 & 27.4 \\
\hline 5 & $\begin{array}{l}0.2 \mathrm{~mm} \text { tungsten } \\
\text { powder }\end{array}$ & 15 & 20 & 30 & 1604 & 1550 & 3121 & 3125 & 48.61 & 50.4 & 49.5 & 1.61 & 33.89 \\
\hline 6 & $\begin{array}{l}0.2 \mathrm{~mm} \text { tungsten } \\
\text { powder }\end{array}$ & 25 & 10 & 60 & 2164 & 2222 & 6255 & 6252 & 65.4 & 64.46 & 64.93 & 0.45 & 36.25 \\
\hline 7 & $1.5 \mathrm{~mm}$ tungsten balls & 5 & 20 & 60 & 4489 & 4577 & 6255 & 6252 & 28.23 & 26.79 & 27.51 & 1.04 & 28.78 \\
\hline 8 & $1.5 \mathrm{~mm}$ tungsten balls & 15 & 10 & 100 & 4989 & 4895 & 10431 & 10419 & 52.17 & 53.02 & 52.59 & 0.36 & 34.42 \\
\hline 9 & $1.5 \mathrm{~mm}$ tungsten balls & 25 & 15 & 30 & 884 & 906 & 3121 & 3125 & 71.68 & 71.01 & 71.34 & 0.22 & 37.07 \\
\hline
\end{tabular}

Table 4: Experimental results of parametric analysis.

The $\mathrm{S} / \mathrm{N}$ ratio response graph is shown in Figure 7. The highest $\mathrm{S} / \mathrm{N}$ levels for all the factors are circled in the figure. Data collected from experiments are analyzed by Analysis of variance (ANOVA) (Table 5).

ANOVA determines how much each parameter contributes to the variation of the results from the effective mean. DF denotes the degree of freedom for each factor. Sx represents the sum of squares. Vx, F and $\mathrm{p} \%$ are mean square, variance ratio and percentage contribution respectively.

Since $\mathrm{C}$ and $\mathrm{D}$ have very little effect on the response (very low values of $\mathrm{Vx}$ ), they are considered as the source of experimental errors. Percentage contributions ( $\mathrm{p} \%$ ) for all control factors in the ANOVA (Table 5), reveal that Factor B (Filler Material Thickness) has the strongest effect on the blocking percentage (shielding capability) of each design.

The shielding material type came the second. Significance tests using the F distribution gave a very similar trend (Table 5).

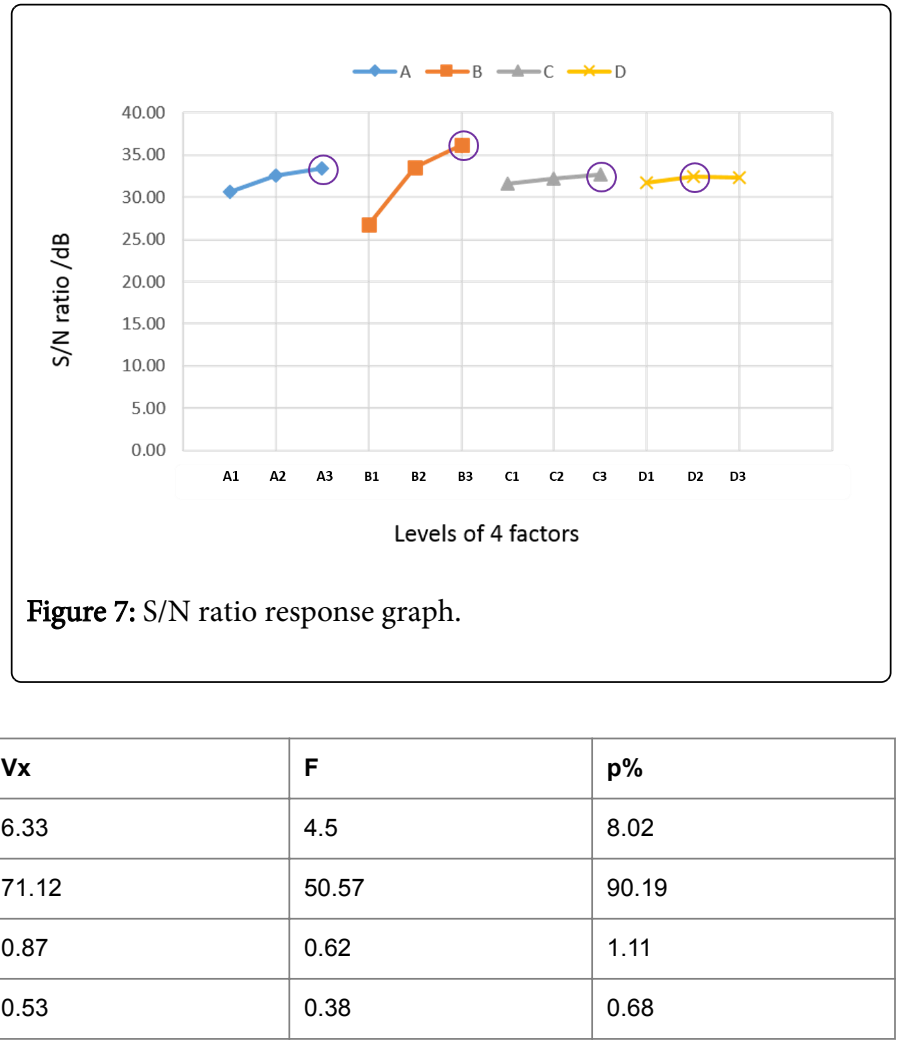


Citation: Kinsaraa A, El-Gizawyab AS, Mab X (2016) Characterization of Attenuating Properties of Novel Composite Radiation Shields. J Nucl

Page 6 of 7

\begin{tabular}{|l|l|l|l|l|l|}
\hline Total & 8 & 157.71 & 19.71 & 56.07 & 100 \\
\hline Error & 4 & 2.81 & 1.41 & & \\
\hline
\end{tabular}

Table 5: ANOVA table.

\section{Analytical model results}

The presented analytical model is used with the nine design conditions presented in Table 2 for predicting the percentage blocking of each case analytically. Analytical predictions are displayed in Table 6.

\begin{tabular}{|l|l|l|l|l|l|l|l|l|l|}
\hline No. & $\mathbf{1}$ & $\mathbf{2}$ & $\mathbf{3}$ & $\mathbf{4}$ & $\mathbf{5}$ & $\mathbf{6}$ & $\mathbf{7}$ & $\mathbf{8}$ & $\mathbf{9}$ \\
\hline Percentage Blocking (\%) & 19.35 & 43.38 & 60.25 & 25.57 & 53.15 & 68.17 & 30.51 & 56.71 & 73.49 \\
\hline
\end{tabular}

Table 6: The results of analytical model.

\section{Simulated model results}

\begin{tabular}{|c|c|c|c|c|c|c|c|c|c|}
\hline No. & 1 & 2 & 3 & 4 & 5 & 6 & 7 & 8 & 9 \\
\hline Percentage Blocking (\%) & 16.78 & 39.39 & 56.97 & 20.17 & 44.73 & 59.93 & 24.37 & 47.69 & 68.01 \\
\hline
\end{tabular}

Table 7: The results of simulation model.

The simulation code MicroShield, is used to assess percentage blocking of each case numerically. Results are shown in Table 7.

\section{Comparison of all results}

The comparison of experimental, analytical and simulated results is listed in Table 8 and Figure 8.

The experimental measurements in the present comparison are taken as a reference for comparison with both the analytical and simulated predictions of percentage blocking of each tested case (design). The experimental measurements are consistently lower than the analytical predictions. Perhaps, the higher percentage blocking values associated with the analytical model are due to the assumption of zero scattering in the analytical model. On the other hand, experimental measurements are consistently higher than the simulated predictions of the percentage blocking of all cases. The differences in the results could be due to the fact that the simulated model assumes a vacuum environment during radiation while the present experimental measurements are taken with atmospheric air environment. Nevertheless, all differences between experimental and predicted values do not exceed 5\% which indicate predictions of any of the reported techniques are acceptable for future studies.

\begin{tabular}{|c|c|c|c|c|c|}
\hline No. & $\begin{array}{l}\text { Experimental result of } \\
\text { blocking \% }\end{array}$ & $\begin{array}{l}\text { Analytical result of } \\
\text { blocking \% }\end{array}$ & $\begin{array}{l}\text { Experimental and Analytical } \\
\text { Difference \% }\end{array}$ & $\begin{array}{l}\text { Simulated result of } \\
\text { blocking \% }\end{array}$ & $\begin{array}{l}\text { Experimental and Simulated } \\
\text { Difference \% }\end{array}$ \\
\hline 1 & 16.28 & 19.35 & -3.07 & 16.78 & -0.50 \\
\hline 2 & 41.35 & 43.38 & -2.03 & 39.39 & 1.96 \\
\hline 3 & 58.22 & 60.25 & -2.03 & 56.97 & 1.25 \\
\hline 4 & 23.45 & 25.57 & -2.12 & 20.17 & 3.28 \\
\hline 5 & 49.50 & 53.15 & -3.65 & 44.73 & 4.77 \\
\hline 6 & 64.93 & 68.17 & -3.24 & 59.93 & 5.00 \\
\hline 7 & 27.51 & 30.51 & -3.00 & 24.37 & 3.14 \\
\hline 8 & 52.59 & 56.71 & -4.12 & 47.69 & 4.90 \\
\hline 9 & 71.34 & 73.49 & -2.15 & 68.01 & 3.33 \\
\hline
\end{tabular}

Table 8: Comparison of experimental, analytical and simulated results. 


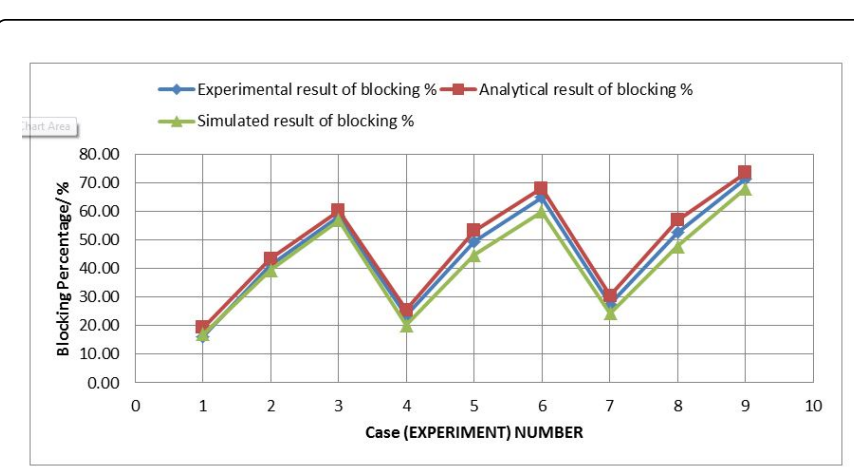

Figure 8: Comparison of experimental, analytical and simulated results.

\section{Conclusions}

The present research aims at determination of attenuating properties of the proposed composite radiation shields using experimental, analytical and numerical simulated techniques. Comparison of results obtained using different techniques indicates that the numerical simulation gives the most conservative values (lowest predicted percentage blocking) which would support a much safer design. Nevertheless, differences among predictions of used techniques never exceeded 5\%. Therefore any of the reported evaluation techniques could be used with reasonable accuracy for development of radiation shield design. The generated results indicate that the filler material thickness of the composite shield has the strongest effect on the shielding capability of the design. Shell material type and thickness have very little effects on the shielding capability and should only be considered for their load carrying capacity and manufacturability by $3-\mathrm{D}$ printing techniques.

\section{Acknowledgments}

The authors wish to acknowledge the financial supports of King Abdulaziz University and the Industrial Technology Development Center (ITDC) at University of Missouri for the present work. The results and statistics provided by students of King Abdulaziz University are also appreciated. Our appreciations are extended to Dr. William Miller, Professor Emeritus of Nuclear Engineering, at University of Missouri Research Reactor (MURR) and Dr. William Kennedy, Medical Physicist, of Ellis Fischel Cancer Center at University of Missouri for their technical support and advice.

\section{References}

1. Kinsara A, El-Gizawy AS, Banoqitah E, Ma X (2016) Review of Leakage from a Linear Accelerator and Its Side Effects on Cancer Patients. J Nucl Med Radiat Ther 7: 1-6.

2. Cuaron JJ, Goodman KA, Lee N, Wu AJ (2013) External beam radiation therapy for locally advanced and metastatic gastrointestinal stromal tumors. Radiation Oncol 8: 1-8.

3. Lawton CA, Yan Y, Lee WR, Gillin M, Firat S, et al. (2012) Long-term results of an RTOG Phase II trial (00-19) of external-beam radiation therapy combined with permanent source brachytherapy for intermediate-risk clinically localized adenocarcinoma of the prostate. Int J Radiat Oncol Biol Phys 82: 795-801.

4. Cupino AC, Hair CD, Angle JF, Caldwell SH, Rich TA, et al. (2012) Does external beam radiation therapy improve survival following transarterial chemoembolization for unresectable hepatocellular carcinoma. Gastrointest Cancer Res 5: 13-17.

5. Huber PE, Debus J, Latz D, Zierhut D, Bischof M, et al. (2001) Radiotherapy for advanced adenoid cystic carcinoma: neutrons, photons or mixed beam? Radiot Oncol 59: 161-167.

6. McCaffrey JP, Shen H, Downton B, Mainegra-Hing E (2007) Radiation attenuation by lead and nonlead materials used in radiation shielding garments. Med Phys 34: 530-537.

7. McCaffrey JP, Mainegra-Hing E, Shen $\mathrm{H}$ (2009) Optimizing non- $\mathrm{Pb}$ radiation shielding materials using bilayers. Med Phys 36: 5586-5594.

8. Schlattl H, Zankl M, Eder H, Hoeschen C (2007) Shielding properties of lead-free protective clothing and their impact on radiation doses. Med Phys 34: 4270-4280.

9. Hill R, Healy B, Holloway L, Baldock C (2007) An investigation of dose changes for therapeutic kilovoltage $\mathrm{x}$-ray beams with underlying lead shielding. Med Phys 34: 3045-3053.

10. Thwaites DI, Tuohy JB (2006) Back to the future: the history and development of the clinical linear accelerator. Phys Med Biol 51: R343R362.

11. Han K, Ballon D, Chui C, Mohan R (1987) Monte Carlo simulation of a cobalt-60 beam. Med Phys 14: 414-419.

12. James AD, James ER, Raymond KW, Peter JB, Patton HM, et al. (2005) NCRP Report 151 Structural shielding design and evaluation for megavoltage $\mathrm{x}$-and gamma-ray radiotherapy facilities. J Radiat Prot 26: 349.

13. Roy RK (2010) A primer on the Taguchi method. Society of Manufacturing Engineers, USA. pp: 1-300.

14. Elmahroug Y, Tellili B, Souga C (2013) Calculation of gamma and neutron shielding parameters for some materials polyethylene-based. Int J Phys Res 3: 33-40.

15. Nondestructive evaluation (NDE)/Nondestructive Testing (NDT) Resource Center.

16. Grove Software/Radiation Software. 